\section{A CASE OF MALIGNANT GOITRE.}

BY CHAONCY PUZEY, L.R.C.P., M.R.C.S.Eng., Surgeon to the Northern Hospital, Liverpool.

Ix the Journat for June 23rd appeared the account of a case of large bronchocele, for which an operation had been performed by Mr. Bennett May, at the Queen's Hospital, Birmingham.

Ten days before this, there had been admitted under my care into the Northern Hospital, Liverpool, a case which must have presented such similar appearances, that a short history of it appears worthy of publication, if only for the sake of comparison; for my case may, to a certain extent, be described in Mr. May's own words.

The patient, a married woman, 55 years old, had been the subject of a (goitrous?) swelling in the front of the neck for many years, without much discomfort. Last Christmas, it began to grow suddenly; but as for years past it had appeared to her sometimes to increase, and then to diminish, she delayed seeking advice until she presented herself at the hospital, on June 13th, on account, principally, of increasing dyspnœa. The tumour presented all the appearances of an unusually large bronchocele, filling up the neck completely in front, so that neither thyroid bone, thyroid cartilage, nor trachea could be felt. On the right side, the outline of the tumour could be well defined posteriorly, and the carotid artery was felt pushed outwards by it; but, on the left side, no defined margin could be made out, and the great vessels appeared to pass deeply behind, even if they were not involved in it. On this side, moreover, the tumour overlapped the clavicle, and the skin over the lower part was dusky red, tense, and adherent. She was unable to lie down on account of dyspnœa. During the day, she was tolerably easy ; but at night, or rather early in the morning, she had severe paroxysms of dyspnœea, caused, apparently, partly by direct pressure on the trachea, partly by implication of the laryngeal nerves. Her voice was faint and husky.

The history of the case, and the appearance of the tumour, led to the diagnosis of malignant disease arising in an ordinary bronchocele; but the question of treatment was more difficult. There appeared to be three methods of active treatment to consider : (1) the removal of the tumour; (2) the tapping of it with trocar or aspirator; and (3) tracheotomy; the last two courses being, of course, only palliative measures for the relief of dyspnca. The first course was considered as precluded, not so much on account of the evident extent of the growth, as because of the impossibility of estimating the limit of the disease; its almost certain malignancy, the infiltration of the skin, and probably of deeper parts, rendering it likely that such an operation, if not immediately fatal, would in no way improve the condition or comfort of the patient. With regard to tapping, there was reason to fear that, although fluid might be drawn off, it would come from some vascular cavity which would speedily fill again, and, perhaps, give rise to troublesome oozing; the result being no relief, but rather the reverse. Tracheotomy did not appear urgently demanded; and it was a question whether it was even possible. A little to the right of the middle line of the neck, there was a slight depression, apparently marking the interval between the two lobes of the thyroid gland, but no trachea could be felt; the isthmus of the gland was clearly enlarged, and filled up this space completely. It was impossible to feel sure where the trachea was, or whither it might have been pushed. In one place, somewhat to the right of the middle line, something like the prominence of the thyroid cartilage was felt, and below this a line was drawn with marking-ink, for guidance, in case threatened suffocation should demand an attempt at relief. But, as regards present treatment, it was decided that operative measures were not desirable. Frequent doses of the ethereal tincture of lobelia were taken by the patient with considerable apparent advantage.

The woman gradually became weaker, but the dyspnoea became no worse, although the left lobe of the tumour increased in size. But on June 24th, her condition became much worse; dyspncea was rather more troublesome; but, in addition, she seemed to have lost the power of swallowing, and her voice had completely gone; her face was rather dusky in hue. Towards the evening she gradually became unconscious, and died quietly and painlessly, probably from slow asphyxia, without any of those distressing symptoms which accompany suffocation from laryngeal obstruction.

At the post mortem examination, the first incision made was as for tracheotomy, along the line marked out before death. On dividing the deep fascia, thick creamy fluid oozed opt, and no trachea could be felt. The fact that tracheotomy would have been a hopeless failure having been demonstrated, the mass was dissected out; together with the larynx, trachea, csophagus, and large vessels, in the course of which process a large cavity in the left lobe gave way, and some ounces of thick chocolate-coloured fluid escaped. On the right side, as anticipated, the mass could be fairly well enucleated, but on the left the growth was found adherent to, or even blended with, muscle, cervical fascia, and the periosteum of the clavicle, and so overlapping and surrounding the large vessels of the neck, that it would have been impossible to clear the growth from them. It was evident that any operative measures could only have " made bad worse."

The contents of the tumour being principally semi-fluid, or soft solid, the mass was, without further examination, immersed in spirit, and sent to the museum of the Royal Infirmary School of Medicine in order that it might be thoroughly examined by the curator, Mr. Frank T. Paul, to whom I am indebted for the accompanying report. Some secondary growths which were found in the lungs were also forwarded for examination.

"The tumour consists of two principal masses, the larger of which is very soft throughout, and has, in its centre, broken down, thus giving rise to a large ragged cavity. In front are some portions of the muscles of the neck adherent to it, and the anterior jugular vein is seen filled with new growth. Posteriorly, the left earotid artery is somewhat flattened by pressure, but not infiltrated, but the internal jugular vein is entirely filled with soft growth. The pneumogastric nerve does not appear to have suffered. There are several cervical glands slightly enlarged. The lesser mass is encapsuled, and has the appearance of soft sarcoma, and can be apparently dissected free, or almost free, from the right lobe of the thyroid, which it indents. The larynx and trachea are bowed to the right, having been displaced about three inches from the middle line of the neck. The pharynx and csophagus are similarly displaced, but none of these parts are infiltrated by the growth. The growths in the lungs present the same soft sarcoma-like appearance.

"The larger mass of the tumour may be supposed to represent the primary growth in the left lobe of the thyroid, and the lesser: a more recent infiltration of the isthmus. The specimen is not yet in a suitable condition for thorough microscopical examination; but a recent section taken from the lesser mass shows it to be freely vasoular, and to consist, over the greater part of its area, of elongated cells, which have a general tendency to become broad and spindle-shaped, with large nuclei, and often with two nuclei. But at one part there is a small area consisting entirely of distinct carcinoma, com. posed of delicate vascular fibrous alveoli, filled with cubical epithelial cells, larger than those of the normal thyroid; and near this is a tract of healthy thyroid tissue.

"There is no doubt that all these elements are present in the growth, but further details cannot be given until sufficient time has elapsed for the preparation of good sections."

\section{REMARKS ON CASES OF MULTIPLE SYNOVITIS, FOLLOWING INJURIES TO JOINTS.}

\section{BY C. MANSELL MOULLIN, F.R.C.S.,} Assistant-Surgeon to the London Hospital.

AMONG the almost endless variety of consequences and complications that may follow sprains and other injuries to joints, there is one which, so far as I can ascertain, has not yet been described; and yet it is difficult to see how it has hitherto escaped. It can scarcely be from its rarity; for, since my attention was first drawn to it by a series of five or six occurring in rapid succession, I have frequently met with others, though I admit that the whole number from which they were selected was very large,perhaps some bundreds; and certainly it cannot arise from any deficiency in features of interest; for if its existence as a distinct variety should be established, it will be found to be as good an example as one could wish of those perplexing affections, which are due to what used to be called the sympathy of one organ with another. I can only conclude, if my conjecture that it has not yet been described be correct, that this variety has hitherto been lost in that vast collection of troubles known as gouty or rheumatic, to which is referred much that is hard to explain.

The uniformity in the essential features of the cases was so close, the differences so slight and so individual, that it is not necessary to give more than a description that will answer for them generally, without dwelling on special peculiarities. The patients were nearly all young adults; with one exception, men of the class which naturally furnishes to the hospitals the majority of the cases of acute 
traumatic synovitis, and suffering, in each case, from either a sprain or a contusion of some large joint. The history ran to the effect that the swelling of the joint for which they came was not immediate; that is, it had not made its appearance, or at least caused sufficient inconvenience to make the patient apply for admission, until some hours had elapsed after the receipt of the injury; and that it had gradually become worse and worse, until it was quite clear there was a very considerable amount of effused liquid in the synovial sac. It was pretty nearly limited to this ; but, sometimes, in the more subcutaneous parts - such as over the inner side of the head of the tibia-a certain amount of puffiness, with tenderness on pressure, could be detected. So far, there is nothing at all out of the common.

The next day, after twenty-four hours' perfect rest in bed, the patient complains of some uneasiness in other joints, more frequently described as a feeling of weakness and stiffness than as amounting to actual pain ; and examination shows at once that they are full of fluid, distending the.synovial sac, but usually to a less degree than the primarily affected articulation. Perhaps, two or three days later, a third set of joints, or a single one, is attacked, but rarely with suff. cient constitutional disturbance to cause a rise of the thermometer. Under the ordinary treatment of rest in bed, with cold applications and pressure, or small blisters, the effused fluid is rapidly absorbed; the secondarily affected joints, as a rule, clearing up as soon as, or even sooner than, the original one.

It does not seem to me, after a careful consideration of these cases, that the terms gouty or rheumatic can be fairly applied to them. I admit that very frequently a local injury, especially an injury to a joint, is credited with being the cause of an attack of gouty or rheumatic synovitis; and I consider it fairly well shown that the hurt, although of course it cannot originate the complaint, can at least determine the exact seat of its outbreak. Indeed, it is quite possible that something of the same sort may occasionally happen in rheumatic fever; for there are numerous examples, too many and too well observed to be passed over, of patients, upon whose statements the greatest reliance can be placed, persisting that the affection of the first joint came on within a very few hours after the infliction of some slight injury. But, even when the fullest allowance is made for these, there remains a considerable number for which no satisfactory explanation is forthcoming. The history of the accident was carefully sifted, in case by any chance more than one joint had been injured; and the strictest inquiry was made as to any evidence of gout or of rheumatism, either in themselves or in their relatives; but none of them would admit it. I am aware that too much reliance must not be placed upon the statements of hospital patients in this respect; but still, there was evidence in strong corroboration in the rapidity of their recovery, in the slight amount of pain from which they suffered; and in the absence of the other clinical features so characteristic of these affections.

In short, there is, in this class of cases, something more than a mere synovitis, arising from a gouty or rheumatic diathesis, or from simple inaction. We are already acquainted with one peculiar affection-acute multiple periostitis - in which it is as morally certain as it well can be, that, in consequence of injury to a particular tissue in one region of the body, similar tissues in other regions become involved in the same way, though with a less degree of severity, in all probability through the medium of the blood; and there is no great inlikelihood in the suggestion, that many inflammatory affections of internal organs, where there is an interval between the attacks, and of which as many examples must be known in medicine as in surgery, may admit of a similar explanation-so far, that is to say, as it is an explanation simply to state a succession of facts, and to compare them with others. It is with these that I would compare cases of consecutive traumatic synovitis; and more particularly with acute multiple periostitis, to which it presents, in its causes, in the sequence of its phenomena, in everything but its severity, such a striking resemblance, that I was at first doubtful whether, owing to the frequent occurrence of slight periostitis after sprains at the attachments of the ligaments, these cases were not essentially periostitic, with consecutive synovitis of the neighbouring joint. The slight degree of pain, especially the absence of nocturnal pain, and the very large amount of effusion, however, render it more likely that the periostitis, when present, was merely an accessory.

The Late Mr. Thomas TURner, J.P., D.L., wTo.-The will of this gentlemen, for many years the treasurer of Guy's Fospital; has just been proved as amounting to over 199,000 , the whole of which he has bequeathed to his widow.

\section{SURGICAL MEMORANDA.}

\section{PROBABLE CAUSE OF NON-UNION OF FRACTURE OF} PATELLA.

G. $\mathrm{R}$, aged 60 , a strong and healthy-looking old man, was admitted into the Infirmary on May 20th, with transverse fracture of the patella. At the time of admission, there was a good deal of ecchymosis around the joint, and the fragments were widely separated. He was placed in the ordinary position, and treated with evaporating lotions and perfect rest, until the effusion had disappeared; the symmetry of the joint aupearing perfect, except a tilting of the fragments, which did not fit together properly after the application of straps and buckles, plaster, etc., which caused me to imagine that there must be something besides the action of the triceps femoris, which was very relaxed. The patient dying on August 15 th, a post mortem examination was made for verification of the diagnosis. There was no attempt at fibrous union; but, on divancating the fragments, three ounces of clotted and partly organised blood was visible, pushing up the fragments, and so causing the displacement and non-co-aptation of the fractured bone. The query arises, might not this clotted blood (or organised blood in the young subject) be the cause of non-union in a great many cases, supposed to be due to the action of the triceps femoris? 'The case appears of interest, in clearly showing the line of treatment which should have been adopted, and the practical utility of early aspiration and putting up in plaster-of-Paris, so doing away with elaborate splints and lotions, and avoiding long confinement to bed. The case also shows the deformity and non-union produced by blood-clot from beneath the fragments, when apparently all effusion had disappeared. W. GEM, L.R.C.S.I., Assistant Medical Officer, City of London Infirmary, Bow.

\section{PATHOLOGICAL MEMORANDA.}

\section{SARCOMA IN THE COMMION FOWL.}

A FEw weeks ago, there was published in the BRITISH MEDICAL Jourvar an account of a case of sarcoma in the common fowl. Another instance may be worth recording. The growth appeared round the margin of the left eye, forming a thick prominent fleshy ring. When I first saw it during the third week in June last, the collapsed eye remained visible at the bottom of a cup-like depression, of which the tumour formed the walls. There was very slight tenderness, and a little dark blood followed a puncture of the soft fleshy mass. Another growth of the size of a pigeon's egg on the lower third of the neck was also felt.

Mr. A. A. Bowlby, of St. Bartholomew's Hospital, has kindly made some sections of the tumour, which, he says, precisely resembles in type that previously described. It consists almost entirely of small round cells with some spindle-shaped ones, the latter possessing more than one nucleus, and forms an infiltrating mass between the layers of subcutaneous tissue.

The hen died in three weeks after I had seen her, without any operation being performed, but at the time she was apparently lay. ing and in good health. It will be interesting to look out for a re-appearance of the disease among the young fowls.

$$
\text { G. PARKer, M.A.Cantab. }
$$

\section{TOXICOLOGICAL MEMORANDA.}

\section{POISONING BY LABURNUM.}

LATELY, no fewer than eight different cases of poisoning by laburnum pods and berries have come before me. The children all presented a pallid and exhausted appearance. Some of them complained of extreme griping pains in the abdomen, nausea, and vomiting öccosionally, the vomited matter consisting of the contents of the stomach, with pieces of the pods and berries scattered in it. The pulse was slow and somewhat feeble, and, in two of the cases scarcely perceptible. One little boy, who had partaken of some of the pods and berries, and whom I watched very carefully, got into a very drowsy condition, and was with difficulty kept awake; occasionally, twitching of the muscles of his upper extremity was noticed. Only in one case was there diarrhosa present along with the romiting. The pupils were either natural or slightly contracted. The symptoms came on from half an hour to an hour after receiving the poison. In some of the cases I administered emetic doses of ipecacuanha wine, and in others five to six grains of sulphate of zino. I found that the sulphate of zino relieved the sufferings quicker, and had not the depreseing effeet of ipecacuenho. 